
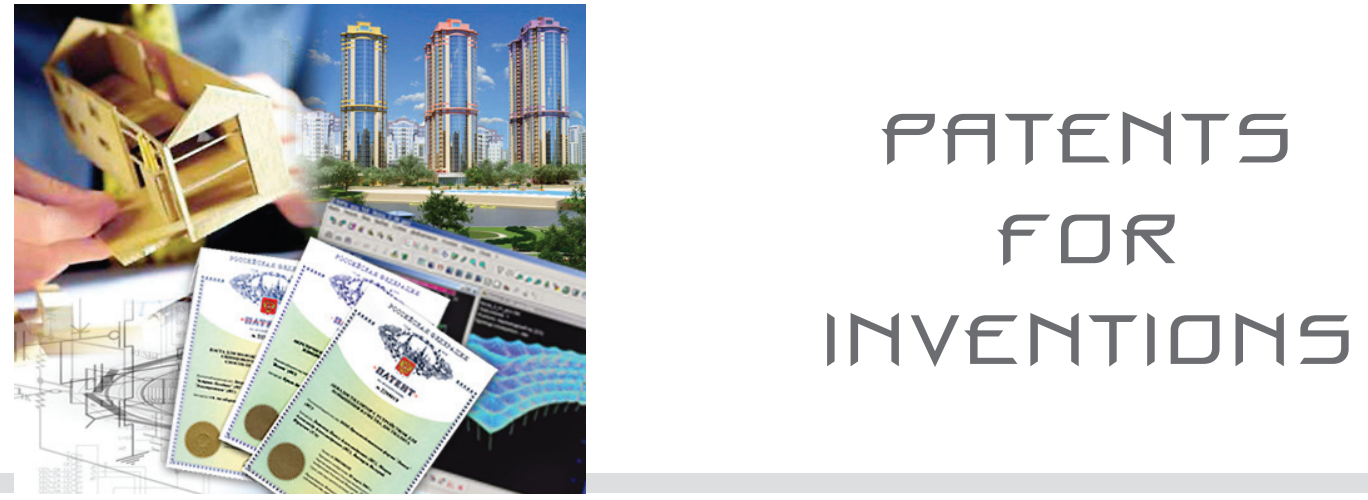

UDC 608; 69.001.5

Author: IVANOV Leonid Alexeevich, Ph.D. in Engineering, Vice President of the International Academy of Engineering. Member of the International Journalist Federation; Gazetny per., block 9, bld.4, Moscow, Russian Federation, 125009, e-mail: L.a.ivanov@mail.ru

Author: MUMINOVA Svetlana Rashidovna, Ph.D. in Engineering, Assistant Professor of Chair of Service Engineering, Russian State University of Tourism and Service; 99, Glavnaya ulitsa, Cherkizovo, Pushkino district, Moscow region, 141221, e-mail: muminovasr@rguts.ru

\title{
NANOTECHNOLOGIES AND NANOMATERIALS: REVIEW OF INVENTIONS. PART 1
}

\section{EXTENDEd Abstract:}

The new technical solutions including inventions in the area of nanotechnology and nanomaterials are efficiently applied in communal and housing services as well as in construction and other joint fields. The invention «Protection system of urban housing and the method to build it (RU 2604933)» refers to construction including environmental structures and can be used to protect cities, objects of national economy from destruction, floods and other types of natural and antropogenic disasters.

Reinforcement of basements of city buildings is performed with barrels with fillers and flexible dampener-ties that receive natural and antropogenic impacts thus providing safety, including ecological one, for urban housing. The system is equipped with solar accumulators that supply energy to people in case of emergencies and additional monitoring system to 
inform people about emergencies. Storm discharge facilities protect cities and towns from floods. All that provides safety of inhabitants' lives and functioning of enterprises when natural and antropogenic disasters such as floods, mud-and-stone flows and other types occur.

The specialists may be also interested in the following nanotechnological inventions: the method to produce hardening mortar (RU 2601885), increase of durability of basalt fiber concrete by nanostructural additives, the method to treat surface and underground waters from titanium and its compounds by means of carbon nanotubes and ultrasound (RU 2575029), material on polymer basis for combined radio- and radiation protection (RU 2605696), thermoelectric heat pump with nanofilm semiconductor sides (RU 2595911), polymer composite nanomaterial (RU 2605590), the method to produce compositions from polymer and nanosize fillers (RU 2586979), the method to produce complex nanodispersed additive for highstrength concrete (RU 2563264) et al.

Key words: nanotechnologies in construction, nanostructural additives, carbon nanotubes, nanosize fillers, nanodispersed additive.

MACHINE-READABLE INFORMATION ON CC-LICENSES (HTML-CODE) IN METADATA OF THE PAPER

$<$ a rel=»license» href=»http://creativecommons.org/licenses/by/4.0/» $><$ img alt=»Creative Commons License» style=»borderwidth:0» src=»https://i.creativecommons.org/l/by/4.0/88x31.png» $/></ \mathrm{a}><$ br $/><$ span xmlns:dct=»http://purl. org/dc/terms/" property=»dct:title» $>$ Nanotechnologies and nanomaterials: review of inventions. Part $1</$ span $>$ by $<$ a xmlns:cc=»http://creativecommons.org/ns\#» href=»Nanotehnologii v stroitel'stve = Nanotechnologies in Construction. 2017, Vol. 9, no. 1, pp. 88-106. DOI: dx.doi.org/10.15828/2075-8545-2017-9-1-88-106» property=»cc:attributionName» rel=»cc:attributionURL» $>$ Ivanov L.A., Muminova S.R. $</ \mathrm{a}>$ is licensed under a $<$ a rel=»license» href=»http:// creativecommons.org/licenses/by/4.0/" $>$ Creative Commons Attribution 4.0 International License $</ \mathrm{a}>$. $<\mathrm{br} />$ Based on a work at <a xmlns:dct=»http://purl.org/dc/terms/» href=» http://nanobuild.ru/en EN/nanobuild-1-2017/» rel=»dct:source»> http://nanobuild.ru/en_EN/nanobuild-1-2017/ $</ \mathrm{a}>$. $<$ br $/>$ Permissions beyond the scope of this license may be available at $<$ a xmlns:cc=»http://creativecommons.org/ns\#»href=»L.a.ivanov@mail.ru»rel=»cc:morePermissions» $>$ L.a.ivanov@mail.ru $</$ a>.

\section{References:}

1. Patents and inventions registered in RF and USSR [Electronic source]. - Access mode: http://www.findpatent.ru/patent/ 260/2604933.html (date of access: 21.12.16). 
2. Patents and inventions registered in RF and USSR [Electronic source]. - Access mode: http://www.findpatent.ru/patent/ 260/2603936.html (date of access: 21.12.16).

3. Patents and inventions registered in RF and USSR [Electronic source]. - Access mode: http://www.findpatent.ru/patent/ 260/2604621.html (date of access: 21.12.16).

4. Patents and inventions registered in RF and USSR [Electronic source]. - Access mode: http://www.findpatent.ru/patent/ 260/2602798.html (date of access: 21.12.16).

5. Patents and inventions registered in RF and USSR [Electronic source]. - Access mode: http://www.findpatent.ru/patent/ 260/2602577.html (date of access: 21.12.16).

6. Patents and inventions registered in RF and USSR [Electronic source]. - Access mode: http://www.findpatent.ru/patent/ 260/2605401.html (date of access: 21.12.16).

7. Patents and inventions registered in RF and USSR [Electronic source]. - Access mode: http://www.findpatent.ru/patent/ 260/2602536.html (date of access: 21.12.16).

8. Patents and inventions registered in RF and USSR [Electronic source]. - Access mode: http://www.findpatent.ru/patent/ 260/2603834.html (date of access: 21.12.16).

9. Patents and inventions registered in RF and USSR [Electronic source]. - Access mode: http://www.findpatent.ru/patent/ 260/2603658.html (date of access: 21.12.16).

10. Patents and inventions registered in RF and USSR [Electronic source]. - Access mode: http://www.findpatent.ru/patent/ 260/2603396.html (date of access: 21.12.16).

11. Patents and inventions registered in RF and USSR [Electronic source]. - Access mode: http://www.findpatent.ru/patent/ 260/2603189.html (date of access: 21.12.16).

12. Patents and inventions registered in RF and USSR [Electronic source]. - Access mode: http://www.findpatent.ru/patent/ 260/2607761.html (date of access: 21.12.16).

13. Patents and inventions registered in RF and USSR [Electronic source]. - Access mode: http://www.findpatent.ru/patent/ 260/2607412.html (date of access: 21.12.16).

14. Patents and inventions registered in RF and USSR [Electronic source]. - Access mode: http://www.findpatent.ru/patent/ 260/2606814.html (date of access: 21.12.16).

15. Patents and inventions registered in RF and USSR [Electronic source]. - Access mode: http://www.findpatent.ru/patent/ 260/2606350.html (date of access: 21.12.16).

16. Ivanov L.A., Muminova S.R. New technical solutions in nanotechnology. Part 5. Nanotehnologii v stroitel'stve $=$ Nanotechnologies in Construction. 2016, Vol. 8, no. 6, pp. 6582. DOI: dx.doi.org/10.15828/2075-8545-2016-8-6-65-82. (In Russian).

17. Patents and inventions registered in RF and USSR [Electronic source]. - Access mode: http://www.findpatent.ru/patent/ 260/2606089.html (date of access: 21.12.16).

18. Ivanov L.A. Results of the theses research in the area of nanotechnologies and nanomaterials. Bulletin of science and education of North-West of Russia. 2016, Vol. 2, no. 4 pp. 1-6. Access mode: http://vestnik-nauki.ru/wp-content/uploads/2016/12/2016-N4-Ivanov. pdf. (date of access: 21.12.16). (In Russian).

19. Ivanov L.A., Muminova S.R. New technical solutions in nanotechnology. Part 1. Nanotehnologii v stroitel'stve $=$ Nanotechnologies in Construction. 2016, Vol. 8, no. 2, pp. 5270. DOI: dx.doi.org/10.15828/2075-8545-2016-8-2-52-70. (In Russian). 
20. Patents and inventions registered in RF and USSR [Electronic source]. - Access mode: http://www.findpatent.ru/patent/ 260/2605696.html (date of access: 21.12.16).

21. Ivanov L.A., Muminova S.R. New technical solutions in nanotechnology. Part 4. Nanotehnologii v stroitel'stve $=$ Nanotechnologies in Construction. 2016, Vol. 8, no. 5, pp. 137156. DOI: dx.doi.org/10.15828/2075-8545-2016-8-5-137-156. (In Russian).

22. Patents and inventions registered in RF and USSR [Electronic source]. - Access mode: http://www.findpatent.ru/patent/ 260/2605590.html (date of access: 21.12.16).

23. Ivanov L.A., Muminova S.R. New technical solutions in nanotechnology. Part 2. Nanotehnologii v stroitel'stve $=$ Nanotechnologies in Construction. 2016, Vol. 8, no. 3, pp. 7491. DOI: dx.doi.org/10.15828/2075-8545-2016-8-3-74-91. (In Russian).

24. Patents and inventions registered in RF and USSR [Electronic source]. - Access mode: http://www.findpatent.ru/patent/ 260/2605401.html (date of access: 21.12.16).

25. Ivanov L.A., Muminova S.R. New technical solutions in nanotechnology. Part 3. Nanotehnologii v stroitel'stve $=$ Nanotechnologies in Construction. 2016, Vol. 8, no. 4, pp. 93110. DOI: dx.doi.org/10.15828/2075-8545-2016-8-4-93-110. (In Russian).

26. Vlasov V.A. The review of patents in the area of nanotechnologies and nanomaterials. Part 4. Nanotehnologii v stroitel'stve = Nanotechnologies in Construction. 2015, Vol. 7, no. 6, pp. 71-88. DOI: dx.doi.org/10.15828/2075-8545-2015-7-6-71-88. (In Russian).

Dear Colleagues!

THE REFERENCE TO THIS PAPER HAS THE FOLLOWING CITATION FORMAT:

Ivanov L.A., Muminova S.R. Nanotechnologies and nanomaterials: review of inventions. Part 1 // Nanotehnologii v stroitel'stve = Nanotechnologies in Construction. 2017, Vol. 9, no. 1, pp. 88-106. DOI: dx.doi.org/10.15828/2075-85452017-9-1-88-106. (In Russian). 

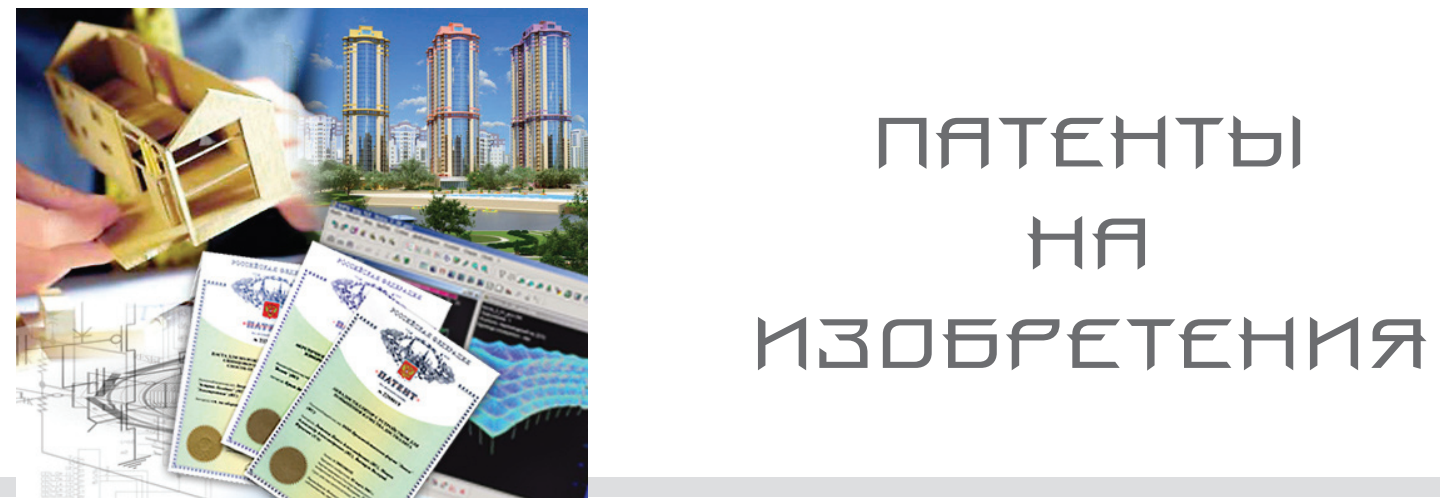

УдК 608; 69.001.5

Автор: ИВАНОВ Леонид Алексеевич, канд. техн. наук, вице-президент Международной инженерной академии, член Международной федерации журналистов; Газетный пер., д. 9, стр. 4, г. Москва, Российская Федерация, 125009, e-mail: L.a.ivanov@mail.ru

Автор: МУмИноВА Светлана Рашидовна, канд. техн. наук, доцент кафедры сервисного инжиниринга, Российский государственный университет туризма и сервиса; 141221, Московская обл., Пушкинский район, дп Черкизово, ул. Главная, 99, e-mail: muminovasr@rguts.ru

\section{НАНОТЕХНОЛОГИИ И НАНОМАТЕРИАЛЫ: ОБЗОР НОВЫХ ИЗОБРЕТЕНИЙ. ЧАСТЬ 1}

\section{АННОТАЦИЯ К СТАТЬЕ (АВТОРСКОЕ РЕЗЮМЕ, РЕФЕРАТ):}

Результаты творческой деятельности ученых, инженеров и специалистов, в т.ч. и изобретения, в области нанотехнологий и наноматериалов позволяют в строительстве, жилищно-коммунальном хозяйстве, смежных отраслях экономики добиться значительного эффекта. Изобретение «Устройство защитной системы городской застройки и способ ее возведения (RU 2604933)» относится к области строительства, в т.ч. природоохранных сооружений, и может быть использовано при защите населенных пунктов, объектов народного хозяйства от разрушения, затопления и т.п. явлений природного и техногенного характера. Усиление оснований городской или иной застройки ведут с помощью системы наполняемых оболочек с заполнителем и гибкими демпферами-связями, воспринимающими природные и техногенные воздействия, обеспечивая безопасность, в т.ч. экологическую, городской застройки. Устройство снабжено солнечными накопителями, которые обеспечивают энергией население в период 
чрезвычайных ситуаций (ЧС) и дополнительной системой мониторинга для оповещения населения о ЧС. Ливнеотводящие устройства позволяют защитить от затопления территории городских застроек/поселений. Обеспечивается безопасность и функционирование жизнедеятельности населения и предприятий при явлениях природного и техногенного характера, таких как паводки, сели и т.п.

Также представляют интерес для специалистов следующие изобретения в области нанотехнологий: способ приготовления укрепляющего раствора (RU 2601885), повышение долговечности базальтофибробетона наноструктурными добавками, способ очистки поверхностных и подземных вод от титана и его соединений с помощью углеродных нанотрубок и ультразвука (RU 2575029), материал на полимерной основе для комбинированной радио- и радиационной защиты (RU 2605696), термоэлектрический тепловой насос с нанопленочными полупроводниковыми ветвями (RU 2595911), полимерный композиционный наноматериал (RU 2605590), способ получения композиций из полимера и наноразмерных наполнителей (RU 2586979), способ изготовления комплексной нанодисперсной добавки для высокопрочного бетона (RU 2563264) и др.

Ключевые слова: нанотехнологии в строительстве, наноструктурные добавки, углеродные нанотрубки, наноразмерные наполнители, нанодисперсная добавка.

\footnotetext{
МАШИНОЧИТАЕМАЯ ИНФОРМАЦИЯ О СС-ЛИЦЕНЗИИ В МЕТАДАННЫХ СТАТЬИ (НTML-КОД):

$<$ a rel=»license» href=»http://creativecommons.org/licenses/by/4.0/»><img alt=»Лицензия Creative Commons» style=»border-width:0» src=»https://i.creativecommons.org/l/by/4.0/88x31.png» $/></ \mathrm{a}><$ br $/>$ Произведение " $<$ span xmlns:dct=»http://purl.org/dc/terms/» property=»dct:title»>Нанотехнологии и наноматериалы: обзор новых изобретений.

Часть $1</$ span>» созданное автором по имени <a xmlns:cc=» http://creativecommons.org/ns\#» href=»Нанотехнологии в строительстве. - 2017. - Том 9, № 1. - C. 88-106. - DOI: dx.doi.org/10.15828/2075-8545-2017-9-1-88-106" property=»cc:attributionName» rel=»cc:attributionURL»> Иванов Л.А., Муминова С.P. $</$ a $>$, публикуется на условиях <a rel=»license» href=»http://creativecommons.org/licenses/by/4.0/»>лицензии Creative Commons "Attribution» ( «Атрибуция») 4.0 Всемирная $</ \mathrm{a}>$. $<\mathrm{br} />$ Основано на произведении с $<$ a xmlns:dct=»http://purl.org/dc/terms $/$ » href=»http:// nanobuild.ru/ru_RU/nanobuild-1-2017/» rel=»det:source»>http://nanobuild.ru/ru_RU/nanobuild-1-2017/</a $>$. $<$ br $/>$ Pa3решения, выходящие за рамки данной лицензии, могут быть доступны на странице $<$ a xmlns:cc=» http://creativecommons. org/ns\#»href=»L.a.ivanov@mail.ru»rel=»cc:morePermissions»>L.a.ivanov@mail.ru</a>.
} 


\section{Устройство защитной системы городской застройки и способ ее возведения (RU 2604933)}

Изобретение относится к области строительства, в т.ч. природоохранных сооружений, и может быть использовано при защите населенных пунктов, объектов народного хозяйства от разрушения, затопления и т.п. явлений природного и техногенного характера.

Устройство защитной системы городской застройки включает водонапорную оболочку, выполненную из композитных материалов, обладающих памятью формы, состоит из канала-лотка, имеющего параболическую или иную форму по периметру из композитного наноматериала, сохраняющего форму и повышенную шероховатость. Канал-лоток состоит из разделительных секций, в которых установлена решетчатая конструкция из вертикальных и горизонтальных элементов из наноматериалов, гибких русловых и береговых связей - демпферов, на которых укреплены верхние грунтонаполняемые и нижние отверждаемые оболочки, а также верхние и нижние и перфорированные водоподпорные сооружения из композитных наноматериалов, укрепленные русловыми анкерами ко дну канала-лотка гибкими связями демпферами, а вантовыми системами - с береговыми и русловыми анкерными устройствами. Откосные части канала-лотка имеют отверстия и дополнительные лотки для освобождения его от наносов. На прилегающих к каналу-лотку боковых территориях устраивают габионные или грунтоармированные подпорные стенки, покрытые материалом с семенами, которые заращиваются растительностью, т.е. применяют агромелиорацию, позволяющую дополнительно обеспечить безопасность населения и объектов городских застроек, которые оповещаются о приближении внешних воздействий и о техническом состоянии данной комплексной системы с помощью контролирующих датчиков и дистанционных устройств, связанных с геоинформационной системой, доступ к которым обеспечивает вантовый мост через каналлоток. Наносы, осевшие в секциях канала-лотка, транспортируются согласно качественному составу через дополнительные лотки с помо- 
щью пневмомеханических устройств, а мутный поток фильтруется в отстойниках-биотенках и далее поступает в водоток. Усиление оснований городской или иной застройки ведет с помощью системы наполняемых оболочек с заполнителем и гибкими демпферами-связями, воспринимающими природные и техногенные воздействия, обеспечивая безопасность, в т.ч. экологическую, городской застройки. Устройство снабжено солнечными накопителями, которые обеспечивают энергией население в период чрезвычайных ситуаций (ЧС) и дополнительной системой мониторинга для оповещения населения о ЧС. Ливнеотводящие устройства позволяют защитить от затопления территории городских застроек/поселений. Способ создания защитной системы городской застройки включает возведение вышеприведенного устройства. Обеспечивается безопасность и функционирование жизнедеятельности населения и предприятий при явлениях природного и техногенного характера, таких как паводки, сели и т.п. [1].

\section{Сварочная проволока с нанокомпозиционным покрытием для сварки высокопрочных сталей (RU 2603936)}

Изобретение относится преимущественно к машиностроению и может быть применено при дуговой сварке и наплавке металлических деталей в среде защитного газа и под флюсом.

Изобретение может быть использовано при дуговой сварке и наплавке металлических деталей из высокопрочных сталей в среде защитного газа и под флюсом. Проволока состоит из металлического стержня с нанокомпозиционным покрытием, состоящим из металлической матрицы и наноразмерных частиц фторидов и боридов редкоземельных металлов с размером частиц менее 1000 нм при следующем соотношении объемов матрицы и наноразмерных частиц в покрытии, \% : металлическая матрица 55-96, наноразмерные частицы фторида или смеси фторидов редкоземельного металла $3-20$, наноразмерные частицы борида или смеси боридов редкоземельного металла 1-25. Сварочная проволока позволяет увеличить прочность, пластичность и ударную вязкость сварных швов высокопрочных сталей [2]. 


\section{Высокопрочный водостойкий органокомпозит и способ его изготовления (RU 2604621)}

Предлагается высокопрочный водостойкий органокомпозит, выполненный из волокнистого наполнителя на основе высокопрочных высокомодульных многофиламентных полиэтиленовых волокон и полимерного связующего на основе эпоксидной смолы с аминным отвердителем. Поверхность наполнителя предварительно обрабатывают в плазме барьерного разряда воздействием импульсного барьерного разряда в воздухе при атмосферном давлении при воздействии переменного напряжения с частотой 10-50 кГц, с удельной мощностью разряда 50-500 Вт/ $\mathrm{m}^{2}$, со скоростью обработки 0,3-7 м/мин. Затем обрабатывают ацетоновым раствором суспензий металлосодержащих наноструктур в углеродполимерных средах. Затем наполнитель сушат, пропитывают полимерным связующим, приготовленным механическим смешением компонентов, и осуществляют формование органокомпозита с температурой отверждения, не превышающей $75^{\circ} \mathrm{C}$. В качестве эпоксидной смолы полимерного связующего органокомпозит содержит смесь эпоксидианового (А) и эпоксиалифатического (Б) олигомеров в соотношении А:Б от 10:1,3 до 10:3. В качестве аминного отвердителя - эвтектическую смесь метафенилендиамина (МФДА) и 4,4'-диаминодифенилметана $\left(4,4^{\prime}\right.$-ДАДФМ) при их массовом соотношении от $22: 78$ до 78:22; и дополнительно содержит смесь олигоэфирциклокарбонатов, форполимер уретановый. Соотношение компонентов в органокомпозите, масс. ч.: волокнистый наполнитель - 250-700; эпоксидиановый олигомер (А) - 100; эпоксиалифатический олигомер (Б) - 13-30; смесь олигоэфирциклокарбонатов 10-20; форполимер уретановый - 5-25; эвтектическая смесь МФДА + 4,4'-ДАДФМ - 28-45. Изобретение позволяет повысить физико-механические свойства и водостойкость органокомпозита при обеспечении экологической чистоты и технологической простоты процесса при реализации промышленного производства [3]. 


\section{Способ получения полимерного композита с наномодифицированным наполнителем (варианты) (RU 2602798)}

Изобретение относится к способу получения полимерного композита с наномодифицированным наполнителем. Способ получения полимерного композита с наномодифицированным наполнителем включает растворение полимера в первом растворителе при температуре $90^{\circ} \mathrm{C}$, обработку ультразвуком находящихся во втором растворителе углеродных нанотрубок (УНТ), смешивание растворенного полимера с раствором УНТ, обработку ультразвуком полученного раствора и термообработку. Способ отличается тем, что раствор УНТ содержит конические углеродные нанотрубки, предварительно функционализированные путем термохимической обработки в смеси азотной и серной кислот гидроксильными и карбоксильными группами. Заявлен также вариант способа. Технический результат - получение полимерного композита с однородным содержанием углеродных нанотрубок [4].

\section{Нанослойное покрытие для высококачественных инструментов (RU 2602577)}

Изобретение относится к нанослойному покрытию режущего инструмента и способу его нанесения на режущий инструмент. Осуществляют нанесение на поверхность режущего инструмента покрытия, содержащего нанослойную структуру из чередующихся нанослоев $\mathrm{A}$, состоящих из $(\mathrm{Al}, \mathrm{Ti}, \mathrm{W}) \mathrm{N}$, и нанослоев $\mathrm{B}$, состоящих из $(\mathrm{Ti}, \mathrm{Si}, \mathrm{W}) \mathrm{N}$. Для нанесения нанослойной структуры используют, по меньшей мере, один источник дугового испарения. Упомянутую нанослойную структуру наносят из чередующихся нанослоев $\mathrm{A}$, имеющих элементный состав, заданный формулой $\left(\mathrm{Al}_{\mathrm{x}} \mathrm{Ti}_{1-\mathrm{x}-\mathrm{y}} \mathrm{W}_{\mathrm{y}}\right) \mathrm{N}$ с $0,50 \leq \mathrm{x} \leq 0,65$ и $0 \leq \mathrm{y} \leq 0,10$, причем коэффициенты, заданные как $\mathrm{x}, 1-\mathrm{x}-\mathrm{y}$ и у соответствуют атомной концентрации алюминия, титана и вольфрама соответственно, и нанослоев $\mathrm{B}$, имеющих элементный состав, заданный формулой $\left(\mathrm{Ti}_{1-\mathrm{z}-\mathrm{u}} \mathrm{Si}_{\mathrm{z}} \mathrm{W}_{\mathrm{u}}\right) \mathrm{N}$ c $0,05 \leq \mathrm{z} \leq 0,30$ и $0 \leq \mathrm{u} \leq 0,10$, причем коэффициенты, заданные как $1-\mathrm{z}-\mathrm{u}, \mathrm{z}$ и и соответствуют атомной концентрации титана, кремния и вольфрама соответственно. Для количественного определения элементов в упомянутом слое А учитывают только упомянутые алюминий, титан и воль- 
фрам. Для количественного определения элементов в упомянутом слое В учитывают только упомянутые титан, кремний и вольфрам. Упомянутый, по меньшей мере, один источник дугового испарения содержит предусмотренное на мишени магнитное приспособление для создания магнитных полей на поверхности мишени и над ней. Упомянутое магнитное приспособление содержит крайние постоянные магниты, центральный постоянный магнит и, по меньшей мере, одну размещенную позади мишени кольцевую катушку, внутренний диаметр которой, определяемый обмотками, меньше или равен диаметру мишени, при этом во время нанесения нанослойной структуры крайние постоянные магниты расположены на расстоянии 6-10 мм от мишени. Проекция крайних постоянных магнитов на поверхность мишени находится дальше от середины поверхности мишени по сравнению с проекцией кольцевой катушки на поверхность мишени, а центральный постоянный магнит расположен позади мишени. Обеспечивается покрытие для высококачественного режущего инструмента, обеспечивающее более высокую производительность по сравнению с режущим инструментом, известным из уровня техники [5].

\section{Способ придания супергидрофобных свойств поверхности металла (RU 2605401)}

Изобретение относится к способу придания супергидрофобных свойств поверхности металла. Воздействуют на упомянутую поверхность сфокусированным лучом импульсного лазерного излучения с длительностью импульсов в наносекундном диапазоне, осуществляют перемещение упомянутого луча относительно упомянутой поверхности по заранее заданному закону. Выбирают характеристики упомянутого лазерного излучения и параметры упомянутого относительного перемещения таким образом, чтобы формировать на упомянутой поверхности многомодальную шероховатость с размерами одновременно в нанометровом и микрометровом диапазонах. Модифицируют упомянутую поверхность веществом с низкой поверхностной энергией - гидрофобизатором. Технический результат заключается в высокой эффективности процесса текстурирования поверхности и обеспечении формирования супергидрофобного состояния многомодальной шероховатости с характерными размерами одновременно в нанометровом (нанометры и/или 
десятки нанометров) и микрометровом (десятки и/или сотни микрон) диапазонах [6].

\section{Способ получения композита диоксид титана/углерод (RU 2602536)}

Изобретение может быть использовано в производстве эффективных электродных материалов в химических источниках тока, сорбентов. Для получения композита диоксид титана/углерод $\mathrm{TiO}_{2} / \mathrm{C}$ проводят термическое разложение титансодержащего прекурсора в инертной атмосфере. В качестве титансодержащего прекурсора используют глицеролат титана $\mathrm{Ti}\left(\mathrm{C}_{3} \mathrm{H}_{7} \mathrm{O}_{3}\right)_{4}$, который нагревают со скоростью 5 град/мин до температуры отжига $360-850^{\circ} \mathrm{C}$ и выдерживают при этой температуре в течение 0,5 часов. Изобретение позволяет получить нанокомпозит диоксид титана/углерод с разнообразной кристаллографической симметрией и с морфологией слабоагломерированных наностержней [7].

\section{Способ получения коллоидных дисперсий графена (RU 2603834)}

Изобретение может быть использовано при получении наномодифицированных композитных материалов для машиностроения, строительства, энергетики, электроники и медицины. Расщепляют графитовый материал нагревом до $50-400^{\circ} \mathrm{C}$ интеркалированных соединений с массовым отношением графита к гептафториду йода от 1:0,77 до 1:5,02 соответственно. Затем проводят ультразвуковое диспергирование расщепленного графита в дисперсной среде - полиаминокарбоновых кислотах или их солях при массовом отношении от 0,000001:1 до 0,01:1 соответственно. Способ получения коллоидных суспензий графена прост и безопасен [8].

\section{Способ получения нанопорошков кристаллических оксидов металлов с использованием криообработки водно-органических золей} (RU 2603658)

Изобретение относится к способу получения кристаллических нанопорошков металлов с размером кристаллитов менее $\leq 10$ нм и может 
быть использовано в химической промышленности, для производства полупродуктов для мелкозернистых керамических материалов. Синтез проводят в водно-органической среде, используя в качестве источников металлов нитраты, хлориды или ацетаты. Для формирования и стабилизации золя используют ацетилацетон-спиртовые растворы $\mathrm{N}, \mathrm{N}$-диметилоктиламина, гексаметилентетрамина или моноэтаноламина. В качестве комплексообразователя используют ацетилацетон. Полученный золь через струйную форсунку диспергируют в жидкий азот, где при скорости охлаждения $>30^{\circ}$ происходит криогрануляция. Полученные гранулы подвергают вакуум-сублимационной сушке с образованием криоаэрогеля, который затем прокаливают при $500^{\circ} \mathrm{C}$ на воздухе в течение 3 ч. Предлагаемый способ обеспечивает технологичный и экологически приемлемый способ получения нанокристаллических оксидов металлов [9].

\section{Оптическое устройство с препятствующим запотеванию покрытием (RU 2603396)}

Изобретение относится к оптическим устройствам, например к таким, как оптические и защитные очки, экраны, защищающие лицо. Устройства содержат прозрачный оптический компонент, прозрачный электропроводный слой покрытия на поверхности оптического компонента, источник питания. Покрытие содержит поперечно-сшитую сетку, содержащую политиофен, углеродные наноструктуры, функциоанализированные тиофеном, и сшивающий агент на основе переходного металла. Слой покрытия может выполнять функцию активного покрытия, препятствующего запотеванию, и предназначен для предотвращения каплеобразной конденсации паров воды на поверхности. Изобретение касается также подложки, имеющей первую поверхность и содержащей находящийся на этой поверхности прозрачный электропроводный слой, содержащий поперечно-сшитую сетку, содержащую поли(3,4-этилендиокситиофен), полистиролсульфоновую кислоту, углеродные нанотрубки, функциоанализированные тиофеном, и сшивающий агент. Изобретение обеспечивает предотвращение запотевания при нанесении данного состава на поверхность таких средств, как экран, защищающий лицо, очки, в том числе их защитные и предохранительные модификации, окуляры и другие подобные устройства [10]. 


\section{Антифрикционная присадка (концентрат) (RU 2603189)}

Изобретение относится к концентрату антифрикционной присадки, содержащему порошок наноалмазов, полученный детонационным синтезом, трансформаторное масло, дополнительно содержит керосин авиационный марки Т-1 и олеиновую кислоту при следующем соотношении компонентов, масс. \%: наноалмазы, полученные детонационным синтезом (ДНА) - 0,30-5,0; олеиновая кислота - 12-50; керосин авиационный марки Т-1 - 6,0-25,0; трансформаторное масло - остальное. Техническим результатом настоящего изобретения является замена алмазосодержащей шихты, содержащей примеси металлов на наноалмазы без примесей, полученные детонационным синтезом, дисперсанта винилсукцинимида более доступным компонентом, а также предельное увеличение содержания ДНА - при сохранении седиментационной устойчивости состава. Область применения: в смазочных композициях, в качестве антифрикционной присадки. Изобретение относится к области получения смазочных композиций с твердыми модификаторами трения, которые используются для смазки машин и механизмов как в процессе обкатки, так и при эксплуатации [11].

\section{Способ тушения пожара нанопорошком с помощью огнетушителя порошкового и огнетушитель порошковый (RU 2607761)}

Изобретение относится к области огнегасящих порошков, выполненных в виде нанопорошка. Огнетушитель порошковый содержит корпус, заполненный огнетушащим порошком, устройство его вытеснения и подачи в очаг пожара, запорно-пусковое устройство и устройство распыления порошка в контролируемой зоне, огнетушащий порошок выполнен в виде нанопорошка. Заявляемое техническое решение просто в эксплуатации и может быть использовано в обычном порошковом огнетушителе для подачи нанопорошка при пожаре в контролируемую зону с присутствием или отсутствием людей [12]. 


\section{Термостойкий полимерный композиционный материал на основе силоксанового каучука и способ его получения (RU 2607412)}

Изобретение относится к теплостойким композиционным материалам, которые могут применяться в различных отраслях техники, и к способу их получения. Описан термостойкий полимерный композиционный материал, содержащий силоксановый каучук в качестве матрицы и многостенные углеродные нанотрубки (УНТ) в качестве наполнителя в количестве 0,1-1,0 мас.ч. на 100 г мас.ч. матрицы, при этом материал обладает термостойкостью (изменение массы при $400^{\circ} \mathrm{C}-$ не более $3,93 \%$ ) и физико-механическими свойствами: модуль упругости при растяжении 0,93-3,63 МПа при относительном удлинении $330-505 \%$. Также описан способ получения полимерного композиционного материала. Технический результат: создание нового полимерного композиционного материала с повышенной термостойкостью и улучшенными механическими свойствами на основе силоксанового каучука в качестве матрицы и углеродных нанотрубок в качестве наполнителя [13].

\section{Теплозащитное нанокомпозитное покрытие и способ его формирования (RU 2606814)}

Изобретение относится к напылению теплозащитных покрытий и может быть использовано в авиастроении и других областях машиностроения при производстве деталей турбинных двигателей и установок. Теплозащитное нанокомпозитное покрытие, содержащее оксид циркония, нанесенное на поверхность изделия из никелевого сплава с использованием магнетронной системы, содержит первичный сплошной слой, градиентный переходный слой и пленку из оксида циркония. Первичный сплошной слой состоит из никелевого сплава, соответствующего составу упомянутого изделия, с цирконием и с добавками стабилизирующего элемента. Градиентный переходный слой содержит две фазы в виде диэлектрической фазы из оксида циркония и металлической фазы из никелевого сплава, соответствующего составу упомянутой поверхности изделия, и циркония с добавкой стабилизирующего элемента, при этом доля оксидной фазы в переходном слое возрастает по мере 
увеличения его толщины. Способ формирования упомянутого теплозащитного нанокомпозитного покрытия на поверхности изделия из никелевого сплава характеризуется тем, что осуществляют формирование на поверхности изделия первичного сплошного слоя из никелевого сплава, соответствующего составу упомянутого изделия, с цирконием и с добавкой стабилизирующего элемента, градиентного переходного слоя, и напыление пленки из оксида циркония до достижения ею требуемой толщины покрытия. Обеспечивается механическая прочность покрытия, повышение его жаропрочности и жаростойкости, а также высокое значение адгезии и когезии [14].

\section{Защитное покрытие на основе полимерного композиционного радиоматериала (RU 2606350)}

Изобретение относится к области радиопоглощающих материалов и покрытий. Описано защитное покрытие на основе полимерного композиционного радиоматериала, содержащее наполнитель и эпоксидную смолу в качестве полимерного связующего, в котором в качестве наполнителя использованы многостенные углеродные нанотрубки (МУНТ) в следующей концентрации, мас. \% : многостенные углеродные нанотрубки $-2-8$, эпоксидная смола - остальное до 100 . Технический результат: получение защитного покрытия, расширяющего область защиты от микроволнового излучения [15].

Также представляют интерес для специалистов следующие изобретения в области нанотехнологий:

- Способ приготовления укрепляющего раствора (RU 2601885) [16].

- Способ исследования информационной емкости поверхности наноструктурированных материалов (RU 2606089) [17].

- Повышение долговечности базальтофибробетона наноструктурными добавками, [18].

- Способ очистки поверхностных и подземных вод от титана и его соединений с помощью углеродных нанотрубок и ультразвука (RU 2575029) [19]. 
- Материал на полимерной основе для комбинированной радио- и радиационной защиты (RU 2605696) [20].

- Термоэлектрический тепловой насос с нанопленочными полупроводниковыми ветвями (RU 2595911) [21].

- Полимерный композиционный наноматериал (RU 2605590) [22].

- Способ изготовления датчика влажности (RU 2579807) [23].

- Способ придания супергидрофобных свойств поверхности металла (RU 2605401) [24].

- Способ получения композиций из полимера и наноразмерных наполнителей (RU 2586979) [25].

- Способ изготовления комплексной нанодисперсной добавки для высокопрочного бетона (RU 2563264) [26].

УВАЖАЕМЫЕ КОЛЛЕГИ!

ПРИ ИСПОЛЬЗОВАНИИ МАТЕРИАЛА ДАННОЙ СТАТЬИ

ПРОСИМ ДЕЛАТЬ БИБЛИОГРАФИЧЕСКУЮ ССЫЛКУ НА НЕЁ:

Иванов Л.А., Муминова С.Р. Нанотехнологии и наноматериалы: обзор новых изобретений. Часть 1 // Нанотехнологии в строительстве. - 2017. - Том 9, № 1. - C. 88-106. - DOI: dx.doi.org/10.15828/2075-8545-2017-9-1-88-106.

\section{DeAR COlleagues!}

THE REFERENCE TO THIS PAPER HAS THE FOLLOWING CITATION FORMAT:

Ivanov L.A., Muminova S.R. Nanotechnologies and nanomaterials: review of inventions. Part $1 / /$ Nanotehnologii v stroitel'stve $=$ Nanotechnologies in Construction. 2017, Vol. 9, no. 1, pp. 88-106. DOI: dx.doi.org/10.15828/2075-85452017-9-1-88-106. (In Russian). 


\section{Библиографический список:}

1. Патенты и изобретения, зарегистрированные в РФ и СССР [Электронный ресурс]. - Pежим доступа: http://www.findpatent.ru/patent/ 260/2604933.html (дата обращения: 21.12.16).

2. Патенты и изобретения, зарегистрированные в РФ и СССР [Электронный ресурс]. - Peжим доступа: http://www.findpatent.ru/patent/ 260/2603936.html (дата обращения: 21.12.16).

3. Патенты и изобретения, зарегистрированные в РФ и СССР [Электронный ресурс]. - Pежим доступа: http://www.findpatent.ru/patent/ 260/2604621.html (дата обращения: 21.12.16).

4. Патенты и изобретения, зарегистрированные в РФ и СССР [Электронный ресурс]. - Pежим доступа: http://www.findpatent.ru/patent/ 260/2602798.html (дата обращения: 21.12.16).

5. Патенты и изобретения, зарегистрированные в РФ и СССР [Электронный ресурс]. - Режим доступа: http://www.findpatent.ru/patent/ 260/2602577.html (дата обращения: 21.12.16).

6. Патенты и изобретения, зарегистрированные в РФ и СССР [Электронный ресурс]. - Peжим доступа: http://www.findpatent.ru/patent/ 260/2605401.html (дата обращения: 21.12.16).

7. Патенты и изобретения, зарегистрированные в РФ и СССР [Электронный ресурс]. - Peжим доступа: http://www.findpatent.ru/patent/ 260/2602536.html (дата обращения: 21.12.16).

8. Патенты и изобретения, зарегистрированные в РФ и СССР [Электронный ресурс]. - Peжим доступа: http://www.findpatent.ru/patent/ 260/2603834.html (дата обращения: 21.12.16).

9. Патенты и изобретения, зарегистрированные в РФ и СССР [Электронный ресурс]. - Pежим доступа: http://www.findpatent.ru/patent/ 260/2603658.html (дата обращения: 21.12.16).

10. Патенты и изобретения, зарегистрированные в РФ и СССР [Электронный ресурс]. - Pежим доступа: http://www.findpatent.ru/patent/ 260/2603396.html (дата обращения: 21.12.16).

11. Патенты и изобретения, зарегистрированные в РФ и СССР [Электронный ресурс]. - Peжим доступа: http://www.findpatent.ru/patent/ 260/2603189.html (дата обращения: 21.12.16).

12. Патенты и изобретения, зарегистрированные в РФ и СССР [Электронный ресурс]. - Peжим доступа: http://www.findpatent.ru/patent/ 260/2607761.html (дата обращения: 21.12.16).

13. Патенты и изобретения, зарегистрированные в РФ и СССР [Электронный ресурс]. - Режим доступа: http://www.findpatent.ru/patent/ 260/2607412.html (дата обращения: 21.12.16). 
14. Патенты и изобретения, зарегистрированные в РФ и СССР [Электронный ресурс]. - Pежим доступа: http://www.findpatent.ru/patent/ 260/2606814.html (дата обращения: 21.12.16).

15. Патенты и изобретения, зарегистрированные в РФ и СССР [Электронный ресурс]. - Peжим доступа: http://www.findpatent.ru/patent/ 260/2606350.html (дата обращения: 21.12.16).

16. Иванов Л.А., Мулинова С.P. Новые технические решения в области нанотехнологий. Часть 5 // Нанотехнологии в строительстве. - 2016. - Том 8, № 6. - С. 65-82. - DOI: dx.doi.org/10.15828/2075-8545-2016-8-6-65-82.

17. Патенты и изобретения, зарегистрированные в РФ и СССР [Электронный ресурс]. - Режим доступа: http://www.findpatent.ru/patent/ 260/2606089.html (дата обращения: 21.12.16).

18. Иванов Л.А. О результатах диссертационных исследований в области нанотехнологий и наноматериалов // Вестник науки и образования Северо-Запада России 2016. - Том 2, № 4. - С. 1-6. - Режим доступа: http://vestnik-nauki.ru/wp-content/ uploads/2016/12/2016-N4-Ivanov.pdf. (дата обращения: 21.12.16).

19. Иванов Л.А., Мулинова С.P. Новые технические решения в области нанотехнологий. Часть 1 // Нанотехнологии в строительстве. - 2016. - Том 8, № 2. - С. 52-70. - DOI: dx.doi.org/10.15828/2075-8545-2016-8-2-52-70.

20. Патенты и изобретения, зарегистрированные в РФ и СССР [Электронный ресурс]. - Pежим доступа: http://www.findpatent.ru/patent/ 260/2605696.html (дата обращения: 21.12.16).

21. Иванов Л.А., Мулинова С.P. Новые технические решения в области нанотехнологий. Часть 4 // Нанотехнологии в строительстве. - 2016. - Том 8, № 5. - С. 137-156. - DOI: dx.doi.org/10.15828/2075-8545-2016-8-5-137-156.

22. Патенты и изобретения, зарегистрированные в РФ и СССР [Электронный ресурс]. - Режим доступа: http://www.findpatent.ru/patent/ 260/2605590.html (дата обращения: 21.12.16).

23. Иванов Л.А., Муминова С.P. Новые технические решения в области нанотехнологий. Часть 2 // Нанотехнологии в строительстве. - 2016. - Том 8, № 3. - С. 74-91. - DOI: dx.doi.org/10.15828/2075-8545-2016-8-3-74-91.

24. Патенты и изобретения, зарегистрированные в РФ и СССР [Электронный ресурс]. - Pежим доступа: http://www.findpatent.ru/patent/ 260/2605401.html (дата обращения: 21.12.16).

25. Иванов Л.А., Мулинова С.P. Новые технические решения в области нанотехнологий. Часть 3 // Нанотехнологии в строительстве. - 2016. - Том 8, № 4. - С. 93-110. - DOI: dx.doi.org/10.15828/2075-8545-2016-8-4-93-110.

26. Власов B.A. Обзор изобретений в области нанотехнологий и наноматериалов. Часть 4 // Нанотехнологии в строительстве. - 2015. - Том 7, № 6. - C. 71-88. - DOI: dx.doi. org/10.15828/2075-8545-2015-7-6-71-88. 